\title{
Exploring and exploiting the fundamental role of microRNAs in tumor pathogenesis
}

This article was published in the following Dove Press journal:

OncoTargets and Therapy

15 November 2013

Number of times this article has been viewed

\section{Qingbao Cheng* \\ Bin Yi* \\ Aihua Wang* \\ Xiaoqing Jiang}

Eastern Hepatobiliary Surgery Hospital, Second Military Medical University, Shanghai, People's

Republic of China

*These authors contributed equally to this work
Correspondence: Xiaoqing Jiang

Eastern Hepatobiliary Surgery Hospital, Second Military Medical University, Changhai Road 225, Shanghai, People's Republic of China

Email jxqI225@yeah.net

\begin{abstract}
RNAs (miRs) are short RNA molecules that are involved in the posttranscriptional regulation of mRNA. The roles of miRs in tumor pathogenesis have only recently become a focus of research. It is becoming increasingly clear that miRs are important regulators of apoptosis, proliferation, invasion, and metastasis in cancer cells during cancer genesis and progression, furthering our understanding of cancer. In the present review, we summarize and evaluate the recent advances in our understanding of the characteristics of miRs as well as their regulated functions in cancer stem cells (CSCs), the epithelial-mesenchymal transition (EMT), and the tumor microenvironment (TM), describing their roles in tumor pathogenesis and their possible use as new therapeutic targets and biomarkers.
\end{abstract}

Keywords: miRNA, cancer stem cell, epithelial-mesenchymal transition, tumor microenvironment

\section{Introduction}

miRNAs (miRs) are a critical class of small, non-coding, endogenous RNAs that have been implicated in the regulation of gene expression regulation. Since 1993, when Lee et $\mathrm{al}^{1}$ discovered the miR family member lin-4 in Caenorhabditis elegans, the roles of miRNAs in various diseases have been investigated. To date, approximately 1,872 precursors and 2,578 mature miRs have been identified in Homo sapiens. Approximately 21-25 nucleotides in length, miRs are a group of short, single-stranded RNAs that are widely expressed in eukaryotes. miRs lack an open reading frame, and thus do not encode proteins. The majority of miRs are evolutionarily conserved among distantly related organisms and may be expressed in a tissue-specific or developmental stage-specific manner. Growing evidence indicates that miRs play critical roles in cancer pathogenesis, chemo/radiotherapy resistance, tumor relapse, and metastasis. In recent years, the number of reports regarding cancer-related miRs has increased dramatically. Cancer stem cells (CSCs) and the epithelial-mesenchymal transition (EMT) play pivotal roles in cancer pathogenesis. ${ }^{2,3}$ In this review, we summarize the recent major findings regarding the miRNA-mediated regulation of CSCs, the EMT, and the tumor microenvironment (TM). Progress in this area has important implications for the development of novel targeted therapeutics.

\section{miRs and CSCs}

CSCs have been identified in a variety of hematological and solid malignancies and play important roles in tumor initiation, maintenance, progression, metastasis, and chemo/radiotherapy resistance. Increasing evidence suggests that miRs differentially 
regulate many properties of $\mathrm{CSCs} .{ }^{4}$ Identification of CSC-related miRs and illustration of their intrinsic molecular regulative mechanisms may provide a better understanding of CSCs. The miR-17-92 polycistron, the first reported oncomir, is often amplified and overexpressed in leukemias, ${ }^{5}$ medulloblastomas, ${ }^{6}$ lung cancer, ${ }^{7}$ and nasopharyngeal carcinomas, ${ }^{8}$ and has been reported to play an oncogenic role by regulating various signaling pathways, including the c-myc, hypoxia-inducible factor $1 \alpha(\mathrm{HIF}-1 \alpha)$, and hedgehog signaling pathways. ${ }^{6,7}$ The first reported tumor suppressive miR was the miR-15/miR-16 cluster, which is often deleted in chronic lymphocytic leukemia (CLL), resulting in Bcl-2 accumulation. ${ }^{9}$ An increasing number of reports regarding oncomiRs and tumor suppressive miRs have been released recently, and in depth mechanistic studies are ongoing. In the current review, we discuss CSC-related miRs in several representative cancers.

Among the various solid cancers, the study of breast cancer stem cells (BCSCs) began relatively early and has been extensive. Let-7, miR-30, miR-16, miR-107, miR-128, and miR-20b were the first miRs identified to be downregulated in BCSCs. ${ }^{10,11}$ More recently, the miR-200c-141, miR-200b200a-429, and miR-183-96-182 clusters were also identified to be significantly downregulated among the 37 differentially expressed miRs in BCSCs. ${ }^{12}$ By performing a miR microarray profiling analysis of breast CSCs in comparison to non-CSC populations, Okuda et $\mathrm{al}^{13}$ recently found that miR-7 is significantly downregulated in metastatic BCSCs. Okuda et al further established a nude mouse metastasis model and reported that miR-7 specifically blocks brain, but not bone, metastasis by modulating $K L F 4$, a gene that is essential for the induction of pluripotent stem cells. Experiments on a series of breast cancer cell lines representing different stages of differentiation revealed that miR-93, a member of the miR106b-25 cluster, negatively regulates the proliferation and differentiation of BCSCs. ${ }^{14} \mathrm{~A}$ renal cancer study published in 2013 demonstrated that the forced expression of miR-141 inhibits cancer cell proliferation by targeting cell division cycle $25 \mathrm{~B}$ phosphatase. ${ }^{15}$ However, because most of these studies focused on deregulated miR profiles, verification of alterations in the expression of validated target genes required further study. Fortunately, recent studies have done just that.

Prostate cancer $(\mathrm{PCa})$ is the most common cancer of the male reproductive system. A decrease in the miR-106b-25 cluster was observed in both primary tumors and distant metastases with early disease recurrence. Subsequent experiments were performed to identify miR-106b-induced global expression changes, and caspase-7 was identified as the target gene. ${ }^{16}$ Another recent prostate cancer study identified 25 upregulated miRs and 36 downregulated miRs in PC-3 sphere cells as compared to adherent cells. Of these dysregulated miRs identified by microarray, miR-143 was validated as the most significantly differentially expressed miR using qRT-PCR. Further analyses suggested that miR-143 may promote prostate cancer metastasis by targeting fibronectin type III domain containing $3 \mathrm{~B} .{ }^{17} \mathrm{CSCs}$ often manifest as spheroid organotypic cultures and have a strong ability to form colonies. Huang et al found that increased levels of miR-143 and miR-145 are associated with decreased cell viability, colony formation, sphere formation, and expression of CSC markers in PC-3 cells from PCa bone metastases, suggesting that decreases in miR-143 and miR-145 in PCa may contribute to PCa bone metastasis by regulating CSC characteristics. ${ }^{18} \mathrm{~A}$ recent study by Hsieh et al demonstrated that miR-320 is significantly downregulated in PCa cells and is a negative regulator of PCa. They observed that increased levels of miR-320 correlate with a decrease in the CSC properties of PCa cells. CD44 is a molecular marker of CSCs. Through global gene expression profiling, members of the Wnt/catenin signaling pathway and CSC markers were confirmed to be targets of miR-320. ${ }^{19}$ Similarly, miR-708 was identified to be downregulated in a CD44+ subgroup of PCa cells and was proposed to be a tumor suppressor miR, regulating $\mathrm{PCa}$ initiation and progression by targeting CD44 and the serine/threonine kinase AKT2. ${ }^{20}$ Downregulation of miR-708 was also demonstrated in the lymph nodes and distal metastases in breast cancer, suggesting a metastasissuppressive role for breast cancer by targeting the endoplasmic reticulum protein neuronatin. ${ }^{21}$

By examining the miR profiles of stem and non-stem cells in glioblastoma (GBM), a 2008 study determined that miR-451, miR-486, miR-425, miR-16, miR-107, and miR-185 are consistently downregulated in GBM CSCs. ${ }^{22}$ A recent study by Guessous et $\mathrm{al}^{23}$ indicated that the expression of miR-10b is increased in GBM tissues and CSCs. Inhibition of miR-10b strongly reduces the invasion and migration of GBM cells, suggesting that it has an oncogenic role. In contrast, miR-204 and miR-125b were demonstrated to be tumor-suppressive regulators of the development of stem cell phenotypes and cell motility in malignant GBM cells and to be markedly downregulated in glioma stem cells. ${ }^{24,25}$ Through a differential miRNA expression screen, miR-204 was found to be significantly downregulated in glioma CSCs and to act as a tumor suppressor miR by targeting the stemness-governing transcription factor SOX4 
and the migration-promoting receptor EphB2 ${ }^{25}$ Chan et $\mathrm{al}^{26}$ illustrated that miR-138 plays a vital role in promoting the proliferation and apoptosis of GBM CSCs. Overexpression of miR-34a in CD44+ PCa cells exerts pronounced inhibitory effects on prostasphere establishment, migration, and metastasis. ${ }^{27}$ Similar results were reported in pancreatic cancer. ${ }^{28}$ The expression of miR-34a in glioma stem cells was also significantly decreased. ${ }^{29}$ Yang et al revealed that decreased levels of miR-34a/c correlates with increased metastatic activity in breast cancer cells and lymph node metastasis, suggesting that an increase in miR-34a/c could contribute to metastases by targeting Fos-related antigen $1 .^{30}$

Pagliuca et $\mathrm{al}^{31}$ reported that miR-143 and miR-145 are significantly downregulated in colorectal tumor cells and that restoration of their expression levels decreases colorectal tumor proliferation, migration, and chemoresistance. Additionally, they showed that miR-143 and miR-145 function as tumor suppressors by regulating CD44, Kruppellike factor 5 (KLF5), Kirsten rat sarcoma 2 viral oncogene homolog (KRAS), and v-Raf murine sarcoma viral oncogene homolog B1 (BRAF). However, another study reported that miR-143 and miR-145 are targeted by TARBP2 to regulate Ewing's sarcoma family tumor CSC clonogenicity and tumor maintenance. ${ }^{32}$ The downregulation of miR-145 in osteosarcoma tissues was recently shown to be correlated with advanced clinical stage, positive distant metastasis, and negative prognosis. ${ }^{33}$

A glioma study indicated that miR-124 is downregulated in both glioma tissues and cell lines. Through an integrated bioinformatics analysis and experimental confirmation, $\mathrm{Xia}$ et $\mathrm{al}^{34}$ identified SNAI2 as a potential direct target of miR-124, thereby restricting stem-like properties. In a study of pancreatic cancer, Wang et $\mathrm{al}^{35}$ reported that miR-124 is silenced by hypermethylation in tumor tissues and that miR-124 inhibits cell proliferation, invasion, and metastasis by targeting Rac 1 and inactivating the MKK4-JNK-c-Jun pathway. A recent ovarian cancer study reported a decrease in miR-29 in cisplatin-resistant cells and showed that the ectopic expression of miR-29 reduces the tumorigenicity of cancer cells. ${ }^{36}$ In breast tumors, miR-29 is significantly downregulated in the CD44+ cell population and is regulated by the female hormone progesterone (P4). miR-29 expands breast tumor CSC properties by directly targeting Krüppellike factor 4 (KLF4). ${ }^{37}$ Wang et $\mathrm{al}^{38}$ found that during bone formation, downregulation of NFkB and YY1 inhibits miR-29 expression. In human rhabdomyosarcoma cells, activation of the NF- $\mathrm{KB} / \mathrm{YY} 1$ signaling pathway often causes miR-29 silencing. However, resumption of the expression of miR-29 results in the inhibition of tumor growth and differentiation. Zhang et $\mathrm{al}^{39}$ recently demonstrated that miR-29 is downregulated by MYC through the MYC-EZH2-miR-29 axis and participates in lymphomagenesis. A study conducted by Zhang et $\mathrm{al}^{40}$ revealed the increased expression of hasmiR-150, has-miR-152, has-mir-888, has-miR-519e, and has-miR-532-5p in CD133-hepatocellular carcinoma (HCC). Moreover, this group demonstrated that the overexpression of miR-150 correlates with significant reductions in CSCs, which are mediated through the negative regulation of c-Myb.

Numerous miR profiling and characterization studies have identified critical roles for miRs in cancer pathogenesis; miRbased therapeutics target CSCs by correcting their aberrant miR expression levels, restoring their suppressive functions and/or blocking their oncogenic properties via the RNAi pathway. Jin et $\mathrm{al}^{41}$ reported that Let-7 is downregulated in $\mathrm{HCC}$ tissues and cells. Another study revealed an increase in Let-7 in HCC stem cells in comparison to HCC cell lines and normal liver stem cells. This increase was found to be associated with decreased chemosensitivity to sorafenib and doxorubicin, possibly through the capase-3-SOCS1-Stat3 pathway. Additionally, miR-181 was identified to play a pivotal role in the regulation of the oncogenic effects of Twist in human HSC invasion by targeting TIMP-3 and NLK. ${ }^{42}$ In another study conducted by Xia et al, silencing of miR-214 in EpCAM+ HCC tumor cells was shown to increase the population of these cells by activating the $\beta$-catenin pathway. ${ }^{43}$ Upregulation of miR-214 was also reported to be related to chemoresistance and metastasis. $\mathrm{Xu}$ et $\mathrm{al}^{44}$ reported that the expression level of miR-214 positively correlates with the proliferation of ovarian CSCs through its regulation of $\mathrm{p} 53$ Nanog signaling pathway.

miR-125b-2 is overexpressed in glioblastoma tissues and glioblastoma stem cells (GSCs) and is downregulated following GSC-induced chemosensitivity to temozolomide. ${ }^{45}$ miR-21, as an oncomiR identified in GSCs, may be another promising chemotherapeutic target. Zhang et al reported that a miR-21 inhibitor sensitizes human GSCs to temozolomide. ${ }^{46}$ By transfecting the has-miR-21 antagomiR into breast cancer cells, Han et $\mathrm{al}^{47}$ found that antagonism of miR-21 could reverse the EMT and decrease the migration and invasion of breast cancer cells. Moreover, antagonism of miR-21 decreases the formation of mammospheres and reduces $\mathrm{CSC}$ characteristics by regulating phosphatase and tensin homolog (PTEN) and inactivating the AKT and ERK1/2 pathways in breast cancer.

miR-145, a tumor suppressor miR, is downregulated in lung cancer, ${ }^{48}$ nasopharyngeal carcinoma, ${ }^{8}$ gastric 
cancer, ${ }^{49,50}$ colorectal cancer, ${ }^{51}$ bladder cancer, ${ }^{52}$ prostrate cancer, ${ }^{53}$ breast cancer, ${ }^{54}$ glioma, ${ }^{55}$ and metastatic melanoma. ${ }^{56} \mathrm{miR}$ profiling microarray technology, combined with quantitative PCR validation, demonstrated that miR-1275 is significantly downregulated during GSC differentiation, and inhibition of miR-1275 in GSCs suppresses their proliferative ability. ${ }^{57} \mathrm{miR}-200 \mathrm{c}$, which targets BIM1, demonstrated a similar tumor suppressor role in melanoma, ${ }^{58}$ prostate cancer, ${ }^{59}$ and head and neck squamous cell carcinomas. ${ }^{60}$

miR-128 functions as a tumor suppressor in breast cancer ${ }^{61,62}$ and glioma. ${ }^{63}$ Using lentivirus-mediated miR-128 transduction in breast CSCs, miR-128 expression levels were demonstrated to sensitize breast CSCs to doxorubicin by regulating $\mathrm{BMI}-1$ and $\mathrm{ABCC}$. Moreover, miR-128 reduction in tissues is correlated with poor prognosis. ${ }^{61}$ Qian et al ${ }^{62}$ found that a decrease in miR-128-2 results in the induction of oncogenic transformation by targeting BMI-1, CSF1, KLF4, LIN28A, NANOG, and SNAIL through the PI3K/AKT and STAT3 signaling pathways in breast cancer.

\section{miRs and the EMT}

The EMT may be the first step in the invasion and metastasis of solid cancers and is related to therapy resistance. Many reports have also linked the EMT to the induction of CSCs in various cancers. Increasing numbers of miRs have been demonstrated to act as critical modulators of the EMT. Members of the miR-200 family function as tumor suppressors in many types of cancers and have been previously reported to prevent the EMT in several solid cancers, including breast cancer, ${ }^{64,65}$ colorectal cancer, ${ }^{66}$ and gastric cancer, ${ }^{67}$ by targeting ZEB1 and ZEB2. miR-200c plays a critical role in the EMT and metastasis in breast cancer cells. A breast cancer study ${ }^{65}$ reported that miR-200c increases the sensitivity of breast cancer cells to doxorubicin, possibly by suppressing the E-cadherin-mediated PTEN/Akt signaling pathway. A recent study indicated that the decreased expression of miR-200 at the invasive front of colorectal cancer is correlated with the EMT and degradation of the basement membrane. However, miR-200 expression was found to be restored in the lymph nodes and vascular lesions, suggesting the involvement of miR-200 in the recapitulation of the primary tumor cells at metastatic sites through the EMT and the mesenchymal-toepithelial transition (MET). ${ }^{66}$ Cong et al demonstrated that miR-200a, miR-200b, and miR-200c are downregulated in gastric cancer tissues, using fluorescence in situ hybridization and suggested that miR-200a regulates the EMT via the Wnt/ $\beta$-catenin pathway. ${ }^{67}$
miR-490-3p is upregulated in HCC tissues and functions as an oncomiR. miR-490-3p regulates the EMT by targeting endoplasmic reticulum-Golgi intermediate compartment protein $3 .{ }^{68}$ In stable has-miR-191-overexpressing cells, overexpression of has-miR-191 was found to induce the EMT, inhibit pan-cytokeratin and E-cadherin, and upregulate $\mathrm{N}$-cadherin by negatively regulating TIMP3. ${ }^{69}$ $\mathrm{Xu}$ et $\mathrm{al}^{70}$ reported that miR-148a suppresses the EMT in HCC cells by inhibiting HPIP expression, possibly through the AKT or ERK/mTOR signaling pathway. The results of this study revealed that miR-148a increases the expression of E-cadherin and downregulates the expression of SNAIL, $\mathrm{N}$-cadherin, and Vimentin. Using cell adhesion assays, Yan et $\mathrm{al}^{71}$ found that miR-10b suppresses HCC cell-matrix adhesion and is involved in the metastatic process by regulating the Eph tyrosine kinase receptor A4-mediated EMT. Several studies have demonstrated the decreased expression of miR-214 in HCC. ${ }^{72-74}$ Using real-time PCR experiments, luciferase reporter assays and Western blot analyses, we demonstrated that a decreased level of miR-214 in metastatic intrahepatic cholangiocarcinoma (ICC) tissues is correlated with an increased level of Twist, suggesting that a decrease in miR-214 may also promote the EMT in ICC cells by targeting Twist. ${ }^{75}$

In breast cancer, numerous miRs have been associated with the EMT, including miR-9, Let-7, miR-200 and miR-24. ${ }^{76-78}$ The miR-106b-25 cluster plays an important role during oncogenesis in breast cancer. Overexpression of the miR-106b-25 cluster activates TGF-beta signaling and induces the EMT. Tellingly, this cluster of miRs also induces a population of cells with a CSC phenotype in a transgenic mouse model. ${ }^{79}$ miR-124 has been reported to be decreased in breast cancer, ${ }^{80}$ glioma, ${ }^{34}$ oral squamous cell carcinomas, ${ }^{81}$ and HCC. ${ }^{82}$ In addition to playing an important role in the regulation of CSC properties, miR-124 also regulates the EMT in breast cancer by targeting the E-cadherin transcriptional repressor Slug. ${ }^{80}$ By establishing a tamoxifenresistant breast cancer model and conducting a subsequent genome-wide miR microarray analysis, Ward et $\mathrm{al}^{83}$ found that decreases in miR-375 contributed to tamoxifen resistance by regulating the EMT.

In lung cancer, miR-23a modulates EMT by targeting E-cadherin, and induces chemoresistance to gefitinib. ${ }^{84} \mathrm{By}$ a screen of a natural epithelial-mesenchymal phenotype cell line pair and a TGF- $\beta$-induced EMT cell model with a miR array, $\mathrm{Xu}$ et al revealed that miR-153 is significantly downregulated during the EMT process and may target SNAI1 and ZEB2. ${ }^{85}$ Hamada et $\mathrm{al}^{86}$ demonstrated that the 
increase in miR-197 in pancreatic cancer induces the EMT by regulating p120 catenin. By comparing the miR expression profiles of HCC tissue from patients with early-recurrent disease to those with non-recurrent disease, Xia et al found that an increase in miR-216a/217 in the early-recurrent group was associated with EMT and CSC properties by targeting SMAD7 and PTEN. Furthermore, they demonstrated that overexpression of miR-216a/217 activates the TGF- $\beta$ signaling pathway and induces chemoresistance to sorafenib by targeting the PI3K-Akt signaling pathway. ${ }^{87}$ A 2012 study showed that the miR-200c expression level is negatively correlated with the EMT and invasion in ICC cells by targeting neural cell adhesion molecule $1 .^{88}$

Expression analyses revealed that the miR-200 family and miR-205 are decreased in EMT models and function negatively by targeting ZEB1 and SIP $1 .{ }^{64}$ Recently, miR-200c and miR-205 were reported to regulate the EMT in prostate cancer cells by targeting ZEB1 and ZEB2, resulting in docetaxel resistance and the overexpression of CSC markers. ${ }^{89}$ miR-205 expression was also demonstrated to be regulated by p63 and to enhance the migration and metastasis of prostate cancer cells. ${ }^{90} \mathrm{Ru}$ et al found that miR-29b is commonly downregulated in prostate cancer and functions as an anti-metastatic miR by regulating the EMT. Ectopic expression of miR-29b in PCa cells induces E-cadherin expression and decreases the expression of N-cadherin, Twist, and SNAIL. ${ }^{91}$ Using a PTEN- and TP53-null PCa model, a recent study showed that both increased levels of Slug and decreased levels of miR-1 and miR-200 are required to initiate the EMT, and that Slug is regulated by miR-1 and miR-200b. ${ }^{92}$

miR-34 has been putatively reported to function as a tumor suppressor miR in many tumors, including colorectal cancer, ${ }^{93,94}$ pancreatic cancer, breast cancer, ovarian cancer, ${ }^{95}$ urothelial cancer, renal cell carcinoma, and soft tissue sarcomas. ${ }^{94}$ miR-34c expression is decreased in breast CSCs, and restoration of its expression inhibits mammosphere formation, CSC phenotypes, and the EMT in breast CSCs by silencing Notch4.${ }^{96}$ Siemens et al reported that the enforced expression of miR-34a induces the MET, downregulates SNAIL, and inhibits the TGF- $\beta$ induced EMT. ${ }^{97}$ Through integrated genomic analyses of 459 serous cases and subsequent functional experiments, a recent ovarian cancer study identified and validated miR506 as an EMT inhibitor and positive prognostic predictor in ovarian cancer by targeting SNAI2. Enhanced expression of miR-506 upregulates E-cadherin expression, suppresses the EMT, and reduces cancer cell proliferation, migration, and invasion. ${ }^{98}$

\section{miRs and TM}

The interaction between cancer cells and the TM plays a critical role in tumor genesis, maintenance, and progression. The TM directly influences tumor cells and acts as an important contributor to cancer progression and metastasis. CSC properties and EMT-related pathways are strongly influenced by the TM. The TM contains the extracellular matrix and various cell types, including fibroblasts, endothelial cells, and immune cells. Dysregulated miRs in the TM could regulate tumor proliferation, invasion, and metastasis.

Several studies have suggested that miRs acting as oncogenes or tumor suppressor genes in cancer-associated fibroblasts (CAFs) regulate tumor progression based on the secretion of certain growth factors and matrix metalloproteinases (MMPs). ${ }^{99}$ Chou et al reported that GATA3 promotes miR-29b expression and suppresses lung metastases in breast cancer. They further identified miR-29b sites in the 3' UTRs of TGF- $\beta$ and many TM-related genes, including VEGF, ANGPTL4, PDGF, LOX, and MMP9, suggesting a metastatic suppressor role for miR-29 by modulating the TM. ${ }^{100}$ Another miR-29 family member, miR-29c, was also shown to alter the TM in nasopharyngeal carcinoma, leading to the dysregulation of 10 extracellular matrix component genes. ${ }^{101}$ In breast cancer, miR-320, which is regulated by PTEN, was demonstrated to be a critical regulator of the TM in CAFs and was shown to regulate the secretome of MMP9 and EMILIN2, which are involved in the regulation of angiogenesis. ${ }^{102}$ The miR-200 family has been demonstrated to play a critical role in the regulation of the EMT and CSC properties. In lung adenocarcinoma, increases in miR-200 are correlated with alterations in the TM, inhibition of metastasis, increases in extracellular matrix proteins (CDH1, EPS8 L2, IRF2BP2, KRT7, KRT8, and KRT19) and peptidases, and alterations in the distribution of cell adhesion proteins in metastatic cell lines. ${ }^{103}$ In PCa, downregulation of miR-15 and miR-16 in CAFs regulates the TM by reducing the repression of Fgf-2 and its receptor, Fgfr1, which forms a molecular circuitry that promotes tumor expansion and invasiveness. ${ }^{104}$

In addition to CAFs, other cells in the TM also display important regulatory roles during tumor progression. With respect to glioma, in the microvascular epithelial cells of the human brain, miR-296 interacts with the 3' UTR of hepatocyte growth factor, downregulating its expression and promoting angiogenesis. ${ }^{105}$ Immune cells are critical components of the TM. By analyzing the clinicopathological data from 288 HCC patients, Yang et al ${ }^{106}$ revealed that hepatitis B virus (HBV) infection is strongly associated with the development of portal venous tumor thrombi (PVTT) and poor 
prognosis. Subsequent experiments were performed on $\mathrm{HCC}$ cell lines and tissue samples, and miR-34a was identified to be associated with $\mathrm{HBV}$-initiated $\mathrm{HCC}$ during the development of PVTT, which is negatively regulated by TGF- $\beta$. This study further demonstrated that the ectopic expression of miR-34a significantly decreases the recruitment of Treg cells in the TM by regulating the expression of the chemokine CCL22. After conducting a series of experiments using transgenic mice, Dudda et $\mathrm{al}^{107}$ reported that the intrinsic expression of miR-155 promotes proliferation and limits apoptosis in effector CD8+ T cells. In addition, this study demonstrated that enforcing miR-155 expression augments the antitumor activity of CD8+ T cells. miRs have also been reported to interact with natural killer (NK) cells. A 2013 study demonstrated that miR-122 enhances the antitumor activity of NK cells, controlling tumor development by regulating the TLR signaling pathway. ${ }^{108}$ Dendritic cells (DCs) were also suggested to be regulated by miRs. Min et al ${ }^{109}$ found that tumor-associated miRs, including miR-22 and miR-503, regulate the survival and longevity of DCs; miR-22 was found to target YWHAZ, and miR-503 was found to target Bcl2. After identifying the $\mathrm{miR}$ expression pattern in tumor-associated macrophages in a mouse breast cancer model, Yang et $\mathrm{al}^{110}$ demonstrated that miR-19a-3p inhibits the metastasis of cancer cells by suppressing M2 macrophage function by targeting Fra-1.

Hypoxia is an important feature of the TM. Several miRs were identified to be dysregulated in response to hypoxic conditions in the TM. miR-495 was identified to be a hypoxiainduced miR in breast CSCs, where it suppresses E-cadherin expression and promotes the EMT. ${ }^{111}$ By conducting experiments on pancreatic cancer cell lines using stem-loop RT-PCR, WST-1 assays, and flow cytometry, Mace et al ${ }^{112}$ found that the expression of miR-21 is induced by hypoxia in pancreatic cancer cells, facilitating apoptosis evasion. Another group found that miR-210 is induced not only during hypoxia but also during iron deficiency. This study further identified that the expression of miR-210 is associated with chronic hypoxia in the TM, suggesting a modulatory role of miR210 during apoptosis and proliferation in cancer cells in the chronic hypoxic TM. ${ }^{113}$ Despite the dysregulated expression of miRs that is induced by hypoxia in the TM, progress has been made in our understanding of the molecular mechanism underlying the miR biogenesis machinery. The EGFR was recently demonstrated to suppress the maturation of specific

Table I microRNAs in tumor pathogenesis

\begin{tabular}{|c|c|c|c|c|c|}
\hline & \multicolumn{2}{|l|}{ Cancer stem cells } & \multicolumn{2}{|c|}{ Epithelial-mesenchymal transition } & \multirow{2}{*}{$\begin{array}{l}\text { Tumor } \\
\text { microenvironment }\end{array}$} \\
\hline & Positive & Negative & Positive & Negative & \\
\hline $\begin{array}{l}\text { Hepatocelluar } \\
\text { carcinoma }\end{array}$ & $\begin{array}{l}\text { Let-7, miR-I8I, } \\
\text { miR-2 } 14\end{array}$ & miR-I50 & $\begin{array}{l}\text { miR-490-3p, } \\
\text { has-miR-191 } \\
\text { miR-216a, miR-217 }\end{array}$ & $\begin{array}{l}\text { miR-I48a, } \\
\text { miR-I0b }\end{array}$ & miR-34a \\
\hline $\begin{array}{l}\text { Intrahepatic } \\
\text { cholangiocarcinoma }\end{array}$ & & & & $\begin{array}{l}\operatorname{miR}-214 \\
\operatorname{miR}-200 c\end{array}$ & \\
\hline Breast cancer & miR-2I, miR-495 & $\begin{array}{l}\text { Let-7, miR-30, miR-I6, miR-I07, } \\
\text { miR-I28, miR-20b, miR-200c-I4I, } \\
\text { miR-200b-200a-429, miR-I83-96-I82 } \\
\text { miR-7, miR-93, miR-708, miR-34a/c, } \\
\text { miR-29 }\end{array}$ & $\begin{array}{l}\text { miR-9, miR-24, } \\
\text { miR-106b-25 } \\
\text { miR-495 }\end{array}$ & $\begin{array}{l}\text { miR-200, miR-124, } \\
\text { miR-375, miR-205, } \\
\text { miR-34a/c }\end{array}$ & $\begin{array}{l}\text { miR-29b, miR-320, } \\
\text { miR-19a-3p, miR-495 }\end{array}$ \\
\hline Prostate cancer & miR-143, & $\begin{array}{l}\text { miR-I06b-25, miR-I43-I45, } \\
\text { miR-320, miR-708, miR-34a }\end{array}$ & & $\begin{array}{l}\text { miR-200, miR-205, } \\
\text { miR-29b, miR-I }\end{array}$ & miR-I5, miR-I6 \\
\hline Renal cancer & & miR-I4I & & & \\
\hline Glioblastoma & $\begin{array}{l}\text { miR-I0b, miR-I38, } \\
\text { miR-I25b-2, miR-2I, } \\
\text { miR-I } 275\end{array}$ & $\begin{array}{l}\text { miR-45 I, miR-486, miR-425, miR-I6, } \\
\text { miR-107, miR-185, miR-204, } \\
\text { miRI25b, miR-34a, miR-I } 24\end{array}$ & & & miR-296 \\
\hline Ovarian cancer & miR-2I4 & & & & \\
\hline Lung carcinoma & & & miR-23a & & miR-200 \\
\hline Gastric cancer & & & & miR-200 & \\
\hline Pancreatic cancer & & miR-34a & miR-197 & & miR-2I \\
\hline Colorectal cancer & & miR-I43, miR-I45 & & miR-200 & \\
\hline $\begin{array}{l}\text { Nasopharyngeal } \\
\text { carcinoma }\end{array}$ & & & & & miR-29c \\
\hline $\begin{array}{l}\text { Ewing's sarcoma } \\
\text { Leukemia }\end{array}$ & & miR-I43, miR-I45 & & & \\
\hline Oral cancer & & & & $\begin{array}{l}\text { miR-I24, miR-I53, } \\
\text { miR-506 }\end{array}$ & \\
\hline
\end{tabular}


tumor suppressor miRs by phosphorylating argonaute 2 and reducing the binding of Dicer and argonaute 2 in the hypoxia TM. ${ }^{114}$ Using bioinformatics in conjunction with experimental validation, Chen et al discovered that Let-7 and miR-103/107 are induced by hypoxia in vascular endothelial cells and consequently target argonaute 1 in miRISC, resulting in the reversal of the suppression of VEGF expression, enhanced angiogenesis, and tumor progression. ${ }^{115}$

\section{Conclusion}

In summary, miRs are closely related to tumors. miRs regulate tumor occurrence and development by affecting related genes and signal pathways, and this process results in changes in miR expression (as shown in Table 1). After further research, miRs are expected to be used for early tumor diagnoses and as therapeutic targets and prognostic indicators. Understanding the molecular mechanism underlying cancer-related miRs in tumor pathogenesis is of paramount importance in providing new avenues for intervention.

\section{Acknowledgments}

We apologize to those whose work could not be cited due to space constraints. This work was supported by grants from the Shanghai Natural Science Foundation (13ZR1410200, 114119b1400), State Scholarship Fund of China (No 2011658507), Youth Research Projects of Shanghai Health Bureau (20114Y125), and Shanghai Talent Development Funds (2010022).

\section{Disclosure}

The authors report no conflicts of interest in this work.

\section{References}

1. Lee RC, Feinbaum RL, Ambros V. The C elegans heterochronic gene lin-4 encodes small RNAs with antisense complementarity to lin-14. Cell. 1993;75:843-854.

2. Scheel C, Weinberg RA. Cancer stem cells and epithelial-mesenchymal transition: concepts and molecular links. Semin Cancer Biol. 2012;22:396-403.

3. Alison MR, Lim SM, Nicholson LJ. Cancer stem cells: problems for therapy? J Pathol. 2011;223:147-161.

4. Garg M. MicroRNAs, stem cells and cancer stem cells. World J Stem Cells. 2012;4:62-70.

5. Li Y, Vecchiarelli-Federico LM, Li YJ, et al. The miR-17-92 cluster expands multipotent hematopoietic progenitors whereas imbalanced expression of its individual oncogenic miRNAs promotes leukemia in mice. Blood. 2012;119:4486-4498.

6. Northcott PA, Fernandez-L A, Hagan JP, et al. The miR-17/92 polycistron is up-regulated in sonic hedgehog-driven medulloblastomas and induced by N-myc in sonic hedgehog-treated cerebellar neural precursors. Cancer Res. 2009;69:3249-3255.

7. Taguchi A, Yanagisawa K, Tanaka M, et al. Identification of hypoxiainducible factor-1 alpha as a novel target for miR-17-92 microRNA cluster. Cancer Res. 2008;68:5540-5545.
8. Chen HC, Chen GH, Chen YH, et al. MicroRNA deregulation and pathway alterations in nasopharyngeal carcinoma. $\mathrm{Br} J$ Cancer. 2009;100:1002-1011.

9. Calin GA, Croce CM. MicroRNA signatures in human cancers Nat Rev Cancer. 2006;6:857-866.

10. Yu F, Yao H, Zhu P, et al. let-7 regulates self renewal and tumorigenicity of breast cancer cells. Cell. 2007;131:1109-1123.

11. Yu F, Deng H, Yao H, Liu Q, Su F, Song E. Mir-30 reduction maintains self-renewal and inhibits apoptosis in breast tumor-initiating cells. Oncogene. 2010;29:4194-4204.

12. Shimono Y, Zabala M, Cho RW, et al. Downregulation of miRNA-200c links breast cancer stem cells with normal stem cells. Cell. 2009;138: 592-603.

13. Okuda H, Xing F, Pandey PR, et al. miR-7 suppresses brain metastasis of breast cancer stem-like cells by modulating KLF4. Cancer Res. 2013;73:1434-1444.

14. Liu S, Patel SH, Ginestier C, et al. MicroRNA93 regulates proliferation and differentiation of normal and malignant breast stem cells. PLoS Genet. 2012;8(6):e1002751.

15. Yu XY, Zhang Z, Liu J, Zhan B, Kong CZ. MicroRNA-141 is downregulated in human renal cell carcinoma and regulates cell survival by targeting CDC25B. Onco Targets Ther. 2013;6:349-354.

16. Hudson RS, Yi M, Esposito D, et al. MicroRNA-106b-25 cluster expression is associated with early disease recurrence and targets caspase-7 and focal adhesion in human prostate cancer. Oncogene. 2013;32(35): 4139-4147.

17. Fan X, Chen X, Deng W, Zhong G, Cai Q, Lin T. Up-regulated microRNA-143 in cancer stem cells differentiation promotes prostate cancer cells metastasis by modulating FNDC3B expression. BMC Cancer. 2013;13:61.

18. Huang S, Guo W, Tang Y, Ren D, Zou X, Peng X. miR-143 and miR-145 inhibit stem cell characteristics of PC-3 prostate cancer cells. Oncol Rep. 2012;28:1831-1837.

19. Hsieh IS, Chang KC, Tsai YT, et al. MicroRNA-320 suppresses the stem cell-like characteristics of prostate cancer cells by downregulating the Wnt/beta-catenin signaling pathway. Carcinogenesis. 2013;34: $530-538$.

20. Saini S, Majid S, Shahryari V, et al. miRNA-708 control of CD44(+) prostate cancer-initiating cells. Cancer Res. 2012;72:3618-3630.

21. Ryu S, McDonnell K, Choi H, et al. Suppression of miRNA-708 by polycomb group promotes metastases by calcium-induced cell migration. Cancer Cell. 2013;23:63-76.

22. Gal H, Pandi G, Kanner AA, et al. MIR-451 and Imatinib mesylate inhibit tumor growth of Glioblastoma stem cells. Biochem Biophys Res Commun. 2008;376:86-90.

23. Guessous F, Alvarado-Velez M, Marcinkiewicz L, et al. Oncogenic effects of miR-10b in glioblastoma stem cells. J Neurooncol. 2013;112: $153-163$.

24. Wu N, Xiao L, Zhao X, et al. miR-125b regulates the proliferation of glioblastoma stem cells by targeting E2F2. FEBS Lett. 2012;586: 3831-3839.

25. Ying Z, Li Y, Wu J, et al. Loss of miR-204 expression enhances glioma migration and stem cell-like phenotype. Cancer Res. 2013;73:990-999.

26. Chan XH, Nama S, Gopal F, et al. Targeting glioma stem cells by functional inhibition of a prosurvival oncomiR-138 in malignant gliomas. Cell Rep. 2012;2:591-602.

27. Liu C, Kelnar K, Liu B, et al. The microRNA miR-34a inhibits prostate cancer stem cells and metastasis by directly repressing CD44. Nat Med. 2011;17:211-215.

28. Ji Q, Hao X, Zhang M, et al. MicroRNA miR-34 inhibits human pancreatic cancer tumor-initiating cells. PLoS One. 2009;4:e6816.

29. Sun L, Wu Z, Shao Y, et al. MicroRNA-34a suppresses cell proliferation and induces apoptosis in U87 glioma stem cells. Technol Cancer Res Treat. 2012;11:483-490.

30. Yang S, Li Y, Gao J, et al. MicroRNA-34 suppresses breast cancer invasion and metastasis by directly targeting Fra-1. Oncogene. 2013;32(36):4294-4303. 
31. Pagliuca A, Valvo C, Fabrizi E, et al. Analysis of the combined action of miR-143 and miR-145 on oncogenic pathways in colorectal cancer cells reveals a coordinate program of gene repression. Oncogene. Epub Novmber 5, 2012.

32. De Vito C, Riggi N, Cornaz S, et al. A TARBP2-dependent miRNA expression profile underlies cancer stem cell properties and provides candidate therapeutic reagents in Ewing sarcoma. Cancer Cell. 2012;21: $807-821$.

33. Tang M, Lin L, Cai H, Tang J, Zhou Z. MicroRNA-145 downregulation associates with advanced tumor progression and poor prognosis in patients suffering osteosarcoma. Onco Targets Ther. 2013;6: 833-838.

34. Xia H, Cheung WK, Ng SS, et al. Loss of brain-enriched miR-124 microRNA enhances stem-like traits and invasiveness of glioma cells. J Biol Chem. 2012;287:9962-9971.

35. Wang P, Chen L, Zhang J, et al. Methylation-mediated silencing of the miR-124 genes facilitates pancreatic cancer progression and metastasis by targeting Rac1. Oncogene. Epub January 32, 2013.

36. Yu PN, Yan MD, Lai HC, et al. Downregulation of miR-29 contributes to cisplatin resistance of ovarian cancer cells. Int J Cancer. Epub August 1, 2013.

37. Cittelly DM, Finlay-Schultz J, Howe EN, et al. Progestin suppression of miR-29 potentiates dedifferentiation of breast cancer cells via KLF4. Oncogene. 2013;32(20):2555-2564.

38. Wang H, Garzon R, Sun H, et al. NF-kappaB-YY1-miR-29 regulatory circuitry in skeletal myogenesis and rhabdomyosarcoma. Cancer Cell. 2008;14:369-381.

39. Zhang X, Zhao X, Fiskus W, et al. Coordinated silencing of MYCmediated miR-29 by HDAC3 and EZH2 as a therapeutic target of histone modification in aggressive B-Cell lymphomas. Cancer Cell. 2012;22:506-523.

40. Zhang J, Luo N, Luo Y, Peng Z, Zhang T, Li S. microRNA-150 inhibits human CD133-positive liver cancer stem cells through negative regulation of the transcription factor c-Myb. Int J Oncol. 2012;40:747-756.

41. Jin H, Lv S, Yang J, et al. Use of microRNA Let-7 to control the replication specificity of oncolytic adenovirus in hepatocellular carcinoma cells. PLoS One. 2011;6:e21307.

42. Meng F, Glaser SS, Francis H, et al. Functional analysis of microRNAs in human hepatocellular cancer stem cells. J Cell Mol Med. 2012;16: 160-173.

43. Xia H, Ooi LL, Hui KM. MiR-214 targets beta-catenin pathway to suppress invasion, stem-like traits and recurrence of human hepatocellular carcinoma. PLoS One. 2012;7:e44206.

44. Xu CX, Xu M, Tan L, et al. MicroRNA miR-214 regulates ovarian cancer cell stemness by targeting p53/Nanog. J Biol Chem. 2012;287: 34970-34978.

45. Shi L, Zhang S, Feng K, et al. MicroRNA-125b-2 confers human glioblastoma stem cells resistance to temozolomide through the mitochondrial pathway of apoptosis. Int J Oncol. 2012;40:119-129.

46. Zhang S, Wan Y, Pan T, et al. MicroRNA-21 inhibitor sensitizes human glioblastoma U251 stem cells to chemotherapeutic drug temozolomide. J Mol Neurosci. 2012;47:346-356.

47. Han M, Liu M, Wang Y, et al. Antagonism of miR-21 reverses epithelial-mesenchymal transition and cancer stem cell phenotype through AKT/ERK1/2 inactivation by targeting PTEN. PLoS One. 2012; 7:e39520.

48. Liu X, Sempere LF, Galimberti F, et al. Uncovering growth-suppressive MicroRNAs in lung cancer. Clin Cancer Res. 2009;15:1177-1183.

49. Takagi T, Iio A, Nakagawa Y, Naoe T, Tanigawa N, Akao Y. Decreased expression of microRNA-143 and -145 in human gastric cancers. Oncology. 2009;77:12-21.

50. Deng H, Guo Y, Song H, et al. MicroRNA-195 and microRNA-378 mediate tumor growth suppression by epigenetical regulation in gastric cancer. Gene. 2013;518(2):351-359.

51. La Rocca G, Badin M, Shi B, et al. Mechanism of growth inhibition by MicroRNA 145: the role of the IGF-I receptor signaling pathway. J Cell Physiol. 2009;220:485-491.
52. Dyrskjot L, Ostenfeld MS, Bramsen JB, et al. Genomic profiling of microRNAs in bladder cancer: miR-129 is associated with poor outcome and promotes cell death in vitro. Cancer Res. 2009;69:4851-4860.

53. Tong AW, Fulgham $\mathrm{P}$, Jay $\mathrm{C}$, et al. MicroRNA profile analysis of human prostate cancers. Cancer Gene Ther. 2009;16:206-216.

54. Wang S, Bian C, Yang Z, et al. miR-145 inhibits breast cancer cell growth through RTKN. Int J Oncol. 2009;34:1461-1466.

55. Yang YP, Chien Y, Chiou GY, et al. Inhibition of cancer stem celllike properties and reduced chemoradioresistance of glioblastoma using microRNA145 with cationic polyurethane-short branch PEI. Biomaterials. 2012;33:1462-1476.

56. Dynoodt P, Speeckaert R, De Wever O, et al. miR-145 overexpression suppresses the migration and invasion of metastatic melanoma cells. Int J Oncol. 2013;42(4):1443-1451.

57. Katsushima K, Shinjo K, Natsume A, et al. Contribution of microRNA1275 to Claudin 11 protein suppression via a polycomb-mediated silencing mechanism in human glioma stem-like cells. J Biol Chem. 2012;287:27396-27406.

58. Liu S, Tetzlaff MT, Cui R, Xu X. miR-200c inhibits melanoma progression and drug resistance through down-regulation of BMI-1. Am J Pathol. 2012;181:1823-1835.

59. Singh S, Chitkara D, Mehrazin R, Behrman SW, Wake RW, Mahato RI. Chemoresistance in prostate cancer cells is regulated by miRNAs and Hedgehog pathway. PLoS One. 2012;7:e40021.

60. Lo WL, Yu CC, Chiou GY, et al. MicroRNA-200c attenuates tumour growth and metastasis of presumptive head and neck squamous cell carcinoma stem cells. J Pathol. 2011;223:482-495.

61. Zhu Y, Yu F, Jiao Y, et al. Reduced miR-128 in breast tumor-initiating cells induces chemotherapeutic resistance via Bmi-1 and ABCC5. Clin Cancer Res. 2011;17:7105-7115.

62. Qian P, Banerjee A, Wu ZS, et al. Loss of SNAIL regulated miR128-2 on chromosome 3p22.3 targets multiple stem cell factors to promote transformation of mammary epithelial cells. Cancer Res. 2012;72:6036-6050.

63. Godlewski J, Nowicki MO, Bronisz A, et al. Targeting of the Bmi-1 oncogene/stem cell renewal factor by microRNA-128 inhibits glioma proliferation and self-renewal. Cancer Res. 2008;68:9125-9130.

64. Gregory PA, Bert AG, Paterson EL, et al. The miR-200 family and miR-205 regulate epithelial to mesenchymal transition by targeting ZEB1 and SIP1. Nat Cell Biol. 2008;10:593-601.

65. Chen Y, Sun Y, Chen L, et al. miRNA-200c increases the sensitivity of breast cancer cells to doxorubicin through the suppression of E-cadherin-mediated PTEN/Akt signaling. Mol Med Rep. 2013;7(5): 1579-1584.

66. Paterson EL, Kazenwadel J, Bert AG, Khew-Goodall Y, Ruszkiewicz A, Goodall GJ. Down-regulation of the miRNA-200 family at the invasive front of colorectal cancers with degraded basement membrane indicates EMT is involved in cancer progression. Neoplasia. 2013;15: 180-191.

67. Cong N, Du P, Zhang A, et al. Downregulated microRNA-200a promotes EMT and tumor growth through the wnt/beta-catenin pathway by targeting the E-cadherin repressors ZEB1/ZEB2 in gastric adenocarcinoma. Oncol Rep. 2013;29:1579-1587.

68. Zhang LY, Liu M, Li X, Tang H. miR-490-3p modulates cell growth and epithelial to mesenchymal transition of hepatocellular carcinoma cells by targeting endoplasmic reticulum-golgi intermediate compartment protein 3 (ERGIC3). J Biol Chem. 2013;288:4035-4047.

69. He Y, Cui Y, Wang W, et al. Hypomethylation of the hsa-miR-191 locus causes high expression of hsa-mir-191 and promotes the epithelialto-mesenchymal transition in hepatocellular carcinoma. Neoplasia. 2011;13:841-853.

70. Xu X, Fan Z, Kang L, et al. Hepatitis B virus X protein represses miRNA148a to enhance tumorigenesis. J Clin Invest. 2013;123(2):630-645.

71. Yan Y, Luo YC, Wan HY, et al. MicroRNA-10a is involved in the metastatic process by regulating Eph tyrosine kinase receptor A4-mediated epithelial-mesenchymal transition and adhesion in hepatoma cells. Hepatology. 2013;57:667-677. 
72. Wong CC, Wong CM, Tung EK, et al. The microRNA miR-139 suppresses metastasis and progression of hepatocellular carcinoma by down-regulating Rho-kinase 2. Gastroenterology. 2011;140: 322-331.

73. Jiang J, Gusev Y, Aderca I, et al. Association of MicroRNA expression in hepatocellular carcinomas with hepatitis infection, cirrhosis, and patient survival. Clin Cancer Res. 2008;14:419-427.

74. Wang Y, Lee AT, Ma JZ, et al. Profiling microRNA expression in hepatocellular carcinoma reveals microRNA-224 up-regulation and apoptosis inhibitor-5 as a microRNA-224-specific target. J Biol Chem. 2008;283:13205-13215.

75. Li B, Han Q, Zhu Y, Yu Y, Wang J, Jiang X. Down-regulation of miR-214 contributes to intrahepatic cholangiocarcinoma metastasis by targeting Twist. FEBS J. 2012;279:2393-2398.

76. Papadimitriou E, Vasilaki E, Vorvis C, et al. Differential regulation of the two RhoA-specific GEF isoforms Net1/Net1A by TGF-beta and miR-24: role in epithelial-to-mesenchymal transition. Oncogene. 2012;31:2862-2875.

77. Ma L, Young J, Prabhala H, et al. miR-9, a MYC/MYCN-activated microRNA, regulates E-cadherin and cancer metastasis. Nat Cell Biol. 2010;12:247-256.

78. Guo L, Chen C, Shi M, et al. Stat3-coordinated Lin-28-let-7-HMGA2 and miR-200-ZEB1 circuits initiate and maintain oncostatin M-driven epithelial-mesenchymal transition. Oncogene. Epub January 14 2013.

79. Smith AL, Iwanaga R, Drasin DJ, et al. The miR-106b-25 cluster targets Smad7, activates TGF-beta signaling, and induces EMT and tumor initiating cell characteristics downstream of Six 1 in human breast cancer. Oncogene. 2012;31:5162-5171.

80. Liang YJ, Wang QY, Zhou CX, et al. MiR-124 targets Slug to regulate epithelial-mesenchymal transition and metastasis of breast cancer. Carcinogenesis. 2013;34:713-722.

81. Hunt S, Jones AV, Hinsley EE, Whawell SA, Lambert DW. MicroRNA124 suppresses oral squamous cell carcinoma motility by targeting ITGB1. FEBS Lett. 2011;585:187-192.

82. Zheng F, Liao YJ, Cai MY, et al. The putative tumour suppressor microRNA-124 modulates hepatocellular carcinoma cell aggressiveness by repressing ROCK2 and EZH2. Gut. 2012;61:278-289.

83. Ward A, Balwierz A, Zhang JD, et al. Re-expression of microRNA-375 reverses both tamoxifen resistance and accompanying EMT-like properties in breast cancer. Oncogene. 2013;32:1173-1182.

84. Cao M, Seike M, Soeno C, et al. MiR-23a regulates TGF-beta-induced epithelial-mesenchymal transition by targeting E-cadherin in lung cancer cells. Int J Oncol. 2012;41:869-875.

85. Xu Q, Sun Q, Zhang J, Yu J, Chen W, Zhang Z. Downregulation of miR153 contributes to epithelial-mesenchymal transition and tumor metastasis in human epithelial cancer. Carcinogenesis. 2013;34:539-549.

86. Hamada S, Satoh K, Miura S, et al. miR-197 induces epithelialmesenchymal transition in pancreatic cancer cells by targeting p120 catenin. J Cell Physiol. 2013;228:1255-1263.

87. Xia H, Ooi LL, Hui KM. MicroRNA-216a/217-induced epithelialmesenchymal transition targets PTEN and SMAD7 to promote drug resistance and recurrence of liver cancer. Hepatology. 2013;58:629-641.

88. Oishi N, Kumar MR, Roessler S, et al. Transcriptomic profiling reveals hepatic stem-like gene signatures and interplay of miR-200c and epithelial-mesenchymal transition in intrahepatic cholangiocarcinoma. Hepatology. 2012;56:1792-1803.

89. Puhr M, Hoefer J, Schafer G, et al. Epithelial-to-mesenchymal transition leads to docetaxel resistance in prostate cancer and is mediated by reduced expression of miR-200c and miR-205. Am J Pathol. 2012;181: 2188-2201.

90. Tucci P, Agostini M, Grespi F, et al. Loss of p63 and its microRNA-205 target results in enhanced cell migration and metastasis in prostate cancer. Proc Natl Acad Sci U S A. 2012;109:15312-15317.

91. Ru P, Steele R, Newhall P, Phillips NJ, Toth K, Ray RB. miRNA-29b suppresses prostate cancer metastasis by regulating epithelial-mesenchymal transition signaling. Mol Cancer Ther. 2012;11:1166-1173.
92. Liu YN, Yin JJ, Abou-Kheir W, et al. MiR-1 and miR-200 inhibit EMT via Slug-dependent and tumorigenesis via Slug-independent mechanisms. Oncogene. 2013;32:296-306.

93. Toyota M, Suzuki H, Sasaki Y, et al. Epigenetic silencing of microRNA-34b/c and B-cell translocation gene 4 is associated with CpG island methylation in colorectal cancer. Cancer Res. 2008;68: 4123-4132.

94. Vogt M, Munding J, Grüner M, et al. Frequent concomitant inactivation of miR-34a and miR-34b/c by CpG methylation in colorectal, pancreatic, mammary, ovarian, urothelial, and renal cell carcinomas and soft tissue sarcomas. Virchows Arch. 2011;458:313-322.

95. Corney DC, Hwang CI, Matoso A, et al. Frequent downregulation of miR-34 family in human ovarian cancers. Clin Cancer Res. 2010;16: 1119-1128

96. Yu F, Jiao Y, Zhu Y, et al. MicroRNA 34c gene down-regulation via DNA methylation promotes self-renewal and epithelial-mesenchymal transition in breast tumor-initiating cells. J Biol Chem. 2012;287: $465-473$.

97. Siemens H, Jackstadt R, Hunten S, et al. miR-34 and SNAIL form a double-negative feedback loop to regulate epithelial-mesenchymal transitions. Cell Cycle. 2011;10:4256-4271.

98. Yang D, Sun Y, Hu L, et al. Integrated analyses identify a master microRNA regulatory network for the mesenchymal subtype in serous ovarian cancer. Cancer Cell. 2013;23:186-199.

99. Wentz-Hunter KK, Potashkin JA. The role of miRNAs as key regulators in the neoplastic microenvironment. Mol Biol Int. 2011;2011:839872.

100. Chou J, Lin JH, Brenot A, Kim JW, Provot S, Werb Z. GATA3 suppresses metastasis and modulates the tumour microenvironment by regulating microRNA-29b expression. Nat Cell Biol. 2013;15: 201-213.

101. Sengupta S, den Boon JA, Chen IH, et al. MicroRNA 29c is downregulated in nasopharyngeal carcinomas, up-regulating mRNAs encoding extracellular matrix proteins. Proc Natl Acad Sci U S A 2008;105:5874-5878.

102. Bronisz A, Godlewski J, Wallace JA, et al. Reprogramming of the tumour microenvironment by stromal PTEN-regulated miR-320. Nat Cell Biol. 2012;14:159-167.

103. Schliekelman MJ, Gibbons DL, Faca VM, et al. Targets of the tumor suppressor miR-200 in regulation of the epithelial-mesenchymal transition in cancer. Cancer Res. 2011;71:7670-7682.

104. Musumeci M, Coppola V, Addario A, et al. Control of tumor and microenvironment cross-talk by miR-15a and miR-16 in prostate cancer. Oncogene. 2011;30:4231-4242.

105. Wurdinger T, Tannous BA, Saydam O, et al. miR-296 regulates growth factor receptor overexpression in angiogenic endothelial cells. Cancer Cell. 2008;14:382-393.

106. Yang P, Li QJ, Feng Y, et al. TGF-beta-miR-34a-CCL22 signalinginduced Treg cell recruitment promotes venous metastases of HBVpositive hepatocellular carcinoma. Cancer Cell. 2012;22:291-303.

107. Dudda JC, Salaun B, JiY, et al. MicroRNA-155 is required for effector $\mathrm{CD} 8+\mathrm{T}$ cell responses to virus infection and cancer. Immunity. 2013;38:742-753.

108. He S, Chu J, Wu LC, et al. MicroRNAs activate natural killer cells through Toll-like receptor signaling. Blood. 2013;121:4663-4671.

109. Min S, Liang X, Zhang M, et al. Multiple tumor-associated microRNAs modulate the survival and longevity of dendritic cells by targeting YWHAZ and Bcl2 signaling pathways. J Immunol. 2013;190: 2437-2446.

110. Yang J, Zhang Z, Chen C, et al. MicroRNA-19a-3p inhibits breast cancer progression and metastasis by inducing macrophage polarization through downregulated expression of Fra-1 proto-oncogene. Oncogene. Epub July 8, 2013.

111. Hwang-Verslues WW, Chang PH, Wei PC, et al. miR-495 is upregulated by E12/E47 in breast cancer stem cells, and promotes oncogenesis and hypoxia resistance via downregulation of E-cadherin and REDD1. Oncogene. 2011;30:2463-2474. 
112. Mace TA, Collins AL, Wojcik SE, Croce CM, Lesinski GB, Bloomston M. Hypoxia induces the overexpression of microRNA-21 in pancreatic cancer cells. J Surg Res. 2013;184(2):855-860.

113. Yoshioka Y, Kosaka N, Ochiya T, Kato T. Micromanaging Iron Homeostasis: hypoxia-inducible micro-RNA-210 suppresses iron homeostasis-related proteins. J Biol Chem. 2012;287:34110-34119.
114. Shen J, Xia W, Khotskaya YB, et al. EGFR modulates microRNA maturation in response to hypoxia through phosphorylation of AGO2. Nature. 2013;497:383-387.

115. Chen Z, Lai TC, Jan YH, et al. Hypoxia-responsive miRNAs target argonaute 1 to promote angiogenesis. J Clin Invest. 2013;123: 1057-1067.

\section{Publish your work in this journal}

OncoTargets and Therapy is an international, peer-reviewed, open access journal focusing on the pathological basis of all cancers, potential targets for therapy and treatment protocols employed to improve the management of cancer patients. The journal also focuses on the impact of management programs and new therapeutic agents and protocols on

\section{Dovepress}

patient perspectives such as quality of life, adherence and satisfaction. The manuscript management system is completely online and includes a very quick and fair peer-review system, which is all easy to use. Visit http://www.dovepress.com/testimonials.php to read real quotes from published authors. 